\title{
/COMMENTARY
}

\section{Some Facts about Predictions}

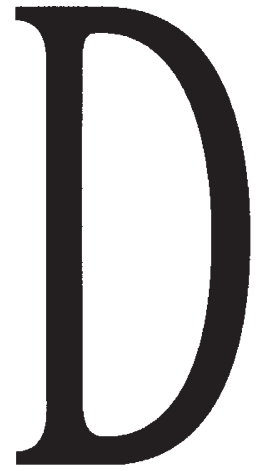
everyone to rank those various possibilities in terms of the likely dates of consummation. At the end of each delphic process, there was a report, stunningly printed with numerous enticing graphics. Lots of people made lots of money out of the process. And lots of companies, which should have had more sense, used the results to plan their corporate strategies.

Looking back over some of those reports in the area of genetic manipulation, one is struck most forcibly not by the bull's-eyes but by the things that everyone got wrong. Some of the duds reflected the failure of the pollsters to consider the social, political, and economic forces, but on other occasions, pooled expertise was simply too optimistic or pessimistic over what now seem to be the relatively simple task of assessing technical feasibility.

According to one delphic study on recombinant DNA breakthroughs, published not much more than a decade ago in Futures (13:128, 1981), biotechnology should, by today, have spawned new nitrogen-fixing plants, and be well on course toward the development of drought-resistant crops. Sickle-cell anemia and phenylketonuria, rather than cystic fibrosis or adenosine deaminase deficiency, were seen as the earliest targets for gene therapy. On the other hand, some participants saw 2025 as the date for "mapping the genetic code of humans." There are abundant lessons here in human fallibility.

Now for an even better example. It comes from David Onions of Glasgow University, speaking at a symposium held in London in May to mark the 150th anniversary of the Royal College of Veterinary Surgeons. Go back ten years, Onions suggested, and consider some of the ideas then being ventilated for the application of transgenic technology to farm animals. There were three principal approaches.

First, following the first results of injecting DNA into the pronuclei of mouse embryos, there was the prospect of increasing the production of domestic animals, and doing so more efficiently. Second, the idea of moving genes around to heighten disease resistance was coming into prominence. Third (and, I recall, so distant and contentious that some commentators saw this more as science fiction than potential
BERNARD DIXON

fact), there was the notion that sheep and other animals might be engineered to produce therapeutic proteins.

As Onions pointed out, a decade ago many wellinformed people would have forecast that these innovations would come precisely in this sequence. In reality, things have happened in exactly reverse order. Back in 1984, it seemed only a matter of time before animal husbandry would benefit from the headlinehitting work of Richard Palmiter and his colleagues. They had injected rat growth hormone DNA into male pronuclei of newly fertilized mouse embryos and found that some of the resulting offspring constitutively expressed the hormone, resulting in rapid growth and enhanced final weight of the animals.

But efforts to mimic that first transgenic mouse experiment by inserting growth hormone gene into livestock met with disaster. The first transgenic pigs had growth deformities, the males had low libido, and the young females did not develop an estrus cycle. "This result exemplifies the need for a thorough knowledge of a system, backed by first rate basic science, before it can be manipulated at the genetic level," Onions concluded.

Next, genetic manipulation to increase resistance to infectious diseases in farm animals was and is an attractive goal. There have even been a few successes, particularly in blocking cellular receptors by expressing viral glycoproteins that normally bind to those receptors. One achievement has come with expression of the envelope glycoprotein of avian infectious leukosis virus, partially protecting poultry against infection with the wild-type virus. But progress in advancing this and alternative strategies to boost disease resistance has been slower than was once imagined.

On the other hand, it is already four years since molecular biologists at Pharmaceutical Proteins (Edinburgh, Scotland) gave the sheep "Tracey" the gene to make human alpha - -antitrypsin, and two years since Bayer AG (Bayerwerk, Germany) did a deal with the Edinburgh-based company to exploit their novel technology. Genzyme (Cambridge, MA) has transgenic goats producing tissue plasminogen activator. And Genepharming Europe (Leiden, the Netherlands) has the bull "Herman" carrying a modified version of the human lactoferrin gene.

So there you have it. For the time being at least, biotechnologists seem to be more adept at solving problems that appear difficult, as opposed to those that seem simple. And they are considerably smarter at these technical crafts than they are at the much more tantalizing task of predicting the future. 